\title{
Reaction of Preschool Children to the Birth of a Sibling
}

\author{
Cecily Legg, M.S.W.* \\ Ivan Sherick, Ph.D. \\ William Wadland \\ University of Michigan Medical Center
}

\begin{abstract}
The experience of becoming and having a sibling is a common situation for many preschool children. In order to clarify the implications of such an event for the older preschool child, the authors have surveyed the literature and interviewed a series of families where there was a second or third birth. This is a preliminary communication where a broad overview of the many variables involved is sought. Varied techniques for preparing the older preschool sibling were observed, as were varied coping mechanisms employed by the older child in adjusting to the change in his family status. Fourteen variables are discussed, and suggestions are made for further research.
\end{abstract}

Everyday life is rich in surprise and novelty for the preschool child. He constantly encounters the previously unknown and is frequently coming upon new situations that push him to make new adaptations which usefully enlarge his repertoire of coping mechanisms. Some new experiences will delight him, while others puzzle, bewilder, confuse, or frighten him, thus putting him under stress. A common stressful situation in early childhood and one with lasting implications is the experience of becoming and having a sibling. For

* Ms. Legg is Senior Research Associate, Child Analytic Study Program, University of Michigan Medical Center, Children's Psychiatric Hospital, Ann Arbor, Michigan 48104. Dr. Sherick is Senior Research Associate, Child Analytic Study Program. Mr. Wadland, at the time he carried out the literature survey and interviews, was a second-year medical student at the University of Michigan. The two senior authors were his consultants. This research has been carried out under the auspices of the Child Psychoanalytic Study Program, Youth Services (Director, Humberto Nagera, M.D.). 
some time the preschool staff have watched with interest the diversity of response that is made to this significant change of status.

A review of the literature has been undertaken followed by a

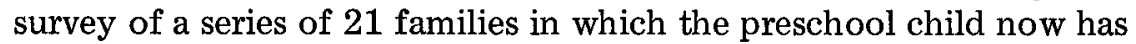
a sibling. In this preliminary study a very broad overview is sought, encompassing the anticipatory period as well as the actual time of birth-nor is a cutoff time designated for response of the preschooler to the growing infant. Thus, in some cases material is available going past the new sibling's first birthday.

\section{Literature Review}

Such a ubiquitous experience as sibling birth might be presumed to have a voluminous literature, but this has not been found to be so. Some probable reasons for this paucity will be offered later. It is noted that while some writers accept the stress of sibling birth as a given, agreeing with Winnicott [1] that "it is so usual as to be called normal when a child is upset at a new one," a few are less comfortable with this commonplace approach. Moore [2], for instance, goes so far as to compare the experience of sibling birth with the uncommon childhood experience of parental death, claiming that either experience has a similar significance for later personality development. Other writers, by denying sibling birth a place in their studies of stressful experiences in childhood, would seem to go to an opposite extreme. Among the literature having sibling birth and the early sibling relationship as its primary topic there appears to be a tendency to overlook the conflictual nature of the experience. Also missing are detailed studies comparing and contrasting the child's manifest response to news of the expected sibling with the level of libidinal development achieved at the time the discovery is made. The majority of writers, although expressing it variously according to disciplinary preference, recognize that the tendency to libidinal regression may be offset by ego progression at such a time. Thus, Einstein and Moss [3] write: "Sibling relationships teach an acceptance of delayed gratification and provide an opportunity to become aware of the rights and obligations of the self and others." By far the most unfortunate trend in the literature is a too broad age grouping, so lessening the possibility of full recognition and study of developmental factors.

The most commonly discussed immediate reactions to the birth of a sibling, as stated in the literature, are direct aggression toward the baby, attention-seeking behavior, and varying degrees of regression, with the alternative of a move toward mastery and independence. When discussing the stressful nature of the experience, Moore 
[2] refers to Henchie's [4] study of 66 young children who experienced the birth of a sibling. Fifteen percent showed a markedly unfavorable reception of the baby and 27 percent slight signs of disfavor. Henchie found that the older siblings' reactions to the baby tended to deteriorate somewhat as the baby grew into a play-disrupting toddler. However, discounting normal squabbling, by age eight only 11 percent of the older siblings were on difficult terms with their younger siblings. The probability of disturbance over the birth of a sibling was found to be greater the younger the age at which the event was experienced. Overt negative reactions to the birth of a sibling were found in 89 percent of subjects under three years, but only 11 percent of those over six years showed this reaction. The sex of the newborn was also seen to be a significant variable in the Henchie study. According to her data, a male infant evokes a more negative response from boys than does a female, while for girls a male infant is more likely to be associated with a disturbance in the mother-child relationship than is the case if the infant is also a girl $(p=.135)$.

Moore [2] mentions that there is some evidence to show that the intellectual development of boys, but not of girls, who gain siblings before they are four years old may slow down somewhat. Moore makes the point that the repression of anger and the attempt to adopt more acceptable behavior is sometimes undertaken at too great a cost by a young child. This can lead to a diminution of creative spontaneity.

Powers [5], discussing the young child's ability to maintain an efficient level of adjustment, correlates the level of adjustment to the levels of various ego functions and reports that she finds only the area of anxiety showing a significant relationship to adjustment. In her study she finds increased problems of adjustment in the birth group that are not matched in the control group. Powers also notes increased adjustment problems in families of lower socioeconomic status, and she attributes the increase to parents being less perceptive and more punitive. Powers does not enter into discussion of possible underlying reasons for this, such as parents being more stressed in their efforts to maintain existence and therefore less able to meet the emotional needs of children.

A doll play study carried out by Moore and Ucko [6] finds that four-year-olds with younger siblings show less affect and aggression in doll play than do those without sibs. This corresponds with the finding of Levy [7] that children with younger siblings show more restricted activity. In Levy's study it would be interesting to have additional information as to the age of the older child at the birth of the younger. A further study by Ucko [8], examining children who 
acquired sibs before the age of four years, reports that these children showed significantly more rigidity in making constructions with wood toys than four-year-olds who had not yet had siblings.

Investigators using the doll play method include Robertson [9]. This author studied a group of nine children whose mothers were pregnant and a control group whose mothers were not pregnant. The control group children were able to express aggression more freely on the second observation, but the study group children repeated "the socialized constructive style of play they had shown before the birth of their siblings." The author writes that "in some, this was felt to reflect genuine family harmony, in others, a strenuous effort to compensate for feelings of jealous resentment which the child could not tolerate in himself."

The literature thus seems to identify and describe manifest behavior, but seldom to discuss this dynamically, or to reflect on the possible unconscious determinants of the behavior; also, when coping mechanisms are noted these are not examined in detail from a developmental point of view. By no means do all children restrict their play as a means of adjusting to sibling birth; as Nagera [10] has shown, some preschool children can bring in an imaginary companion as a means of alleviating some of the stress associated with the birth of a sibling.

In his classic work based on doll play studies, Levy [7] notes two disadvantages of the doll play situation-namely, attentiongetting behavior in older siblings is missing, and the regressive tendencies due to sibling birth are not as clearly seen as they appear in real life. Nevertheless, a particularly pertinent finding of Levy's study is that "the closer the relationship of a child to mother, the greater is the disturbance caused by the intruder and hence the more likely overt manifestation of hostility." He finds that as overprotection from the mother decreases with increase in family size, so does hostility toward the birth of a sibling. Levy's study was done prior to Mahler's work on the separation-individuation phase and thus does not correlate the child's reaction to sibling birth with the subphase reached in the separation-individuation process. Levy [7: p. 456] reports that the sibling reaction can occur even before the birth of the sibling when it "is primarily to privation or change in terms of care, affection, attention, or to differences in the appearance or routine of the child's familiar world. ... The baby may not be perceived as the object of rivalry, if at all, for months or even years, especially when the age difference is but two years." Levy's reference is to psychological separation from the mother. But in this society implicit in the ac- 
tual birth of the sibling is usually physical separation from the mother as well, due to the routine of hospitalizing women at the time of delivery. This may in some cases be the young child's first experience of being separated from the mother for a whole day. Among the many variables that enter into a study of reaction to sibling birth the factor of separation from the mother is one of the most complicated; interlinked with it are the increase or decrease of father involvement with the child, probable entry of unfamiliar adults into the home, and even a possible temporary change of living quarters.

In a study of four young children fostered under optimal circumstances during hospitalization of the mothers for delivery the Robertsons [11] write that "after return home there was in all four children an increase of hostility against the mother which carried some potential for disharmony in the mother-child relationship." These authors find that their study throws

no light on reasons for separation as variables influencing behavior during separation since all the children were separated for the same reason, the birth of a second child. It is sometimes said that the prospect of a new and rivalrous sibling must be an additional stress. We had no access to fantasy, but the manifest behavior of the four fostered children suggested the expected babies impinged hardly at all until they were physically present and taking their share of the parents' attention.

Thomas, Birch, Chess, and Robbins [12], studying the effects of important socialization experiences in early childhood on a population of 110 normal children, whose development was followed from the first months of life, report that in 18 families a younger sibling was born. The authors record that over half of the older children showed disturbance over the event.

Two main types of disturbances noted were (1) reversion to more infantile patterns of functioning in socialization, feeding, sleeping, and toileting, (2) aggressive behavior toward the new baby. In six instances the reaction was mild and transient, in one moderate and in three prolonged and severe. Three children showed no discernible disturbance in functioning and five actually showed an improvement in their social responses. [12: p. 800]

Several of the findings of these authors parallel our own data: for example, first children are found to show more intense reactions than those who already have a sibling; children whose fathers are considerably involved with them show good ability to tolerate some lessening 
of maternal attention; and it appears, from our observations, that 18 months is a critical age at which to get a new sibling. In addition, Thomas et al. [12: pp. 800-801] find

a definite relationship between the characteristics of primary reactivity in the child and the type of response to the birth of a sibling. Those children who from early infancy on showed mild positive regular responses with quick adaptability to new stimuli, such as the bath, change in sleep schedule and the introduction of new foods, manifested a similar pattern with the new baby. In this group disturbances were minimal or nonexistent.

The seeming paucity of literature on the topic of reaction to sibling birth has been stated. It is our impression that such literature is in fact more extensive than may be apparent. The appearance of early sibling relationships cannot be overlooked. It is to clinical papers, therefore, perhaps, rather than to formal studies that we should turn for a closer scrutiny of the vicissitudes of the early sibling relationships and their impact upon personality development. The reasons for the slender literature in terms of topic-specific studies can be assumed to have several differing bases. However, the quantity and complexity of the variables that are involved cannot have failed to have had a negative influence on would-be investigators.

\section{The Study}

A modest open-ended pilot study has been planned in order to determine and examine some of the significant variables as they are to be found in the small study population to which we have easy access. Data have been collected on 21 families, and since in 4 of these information has been obtained on more than one older sibling's response to the birth of a younger one, the number of children in the series is 25 . The term "preschool child" is taken to mean any child who has not yet started in kindergarten. The study plan provided for all mothers to come to the hospital for an interview. Early in the series, however, the advantages of the interviewer going to the home became manifest, and this procedural change was made. One mother requested not to come to the hospital, nor did she want a home interview; her preference was to be interviewed in the university library where she studies regularly. In all but two instances data were obtained from only one parent, the mother. In the two exceptions both parents were home and participated jointly in the interview.

\section{Population}

Of the families studied, 15 families or 71 percent now have or did have in the recent past a child in the Child Analytic Study Program (CASP) preschool. The remaining six families or 29 percent who are not involved in the CASP pre- 
school program have been introduced through friends or through contact with a local private day care facility.

All fathers in the study families have a college education. Twelve fathers (57.1 percent) are on the university faculty, four fathers (19 percent) are either graduate or doctoral students, and five fathers ( 23.8 percent) are variously employed. All mothers in the study are college educated, and eight mothers (38.9 percent) continued with career plans in full or modified form subsequent to the birth of the child whose response to sibling birth we studied, so that varying amounts of substitute mothering have been experienced by these children. The sample is thus seen to be a college-educated group. Ethnic backgrounds are varied and include several bilingual families who do not speak English in the home. In addition there is one Afro-American and one American Indian family.

All children about whom data have been collected are considered to be both physically and psychologically healthy and to be within normal developmental levels for their age. Ages of children in the study ranged from 111/2 months to 5 years 2 months at the time of sibling birth, giving a broad scatter with some tendency to cluster between 12 and 27 months. Nineteen children (76 percent of the study subjects) were within this age bracket at the time of sibling birth. There are 17 (68 percent) boys and 8 (32 percent) girls in the study. Nine boys ( 52.9 percent) and five girls (62.5 percent) received a same sex sib, leaving eight boys (47.1 percent) and three girls ( 37.5 percent) who had opposite sex sibs.

\section{Data Collection}

Data have been collected by means of a personal interview with the parent(s). Since this has been an open-ended pilot study with no previously set up hypothesis to test, an instrument has not been devised. In order to achieve as much consistency as possible in the nature of data collected an interview outline has been drawn with three broad temporal categories of desired information, that is, the child's response to the sibling before the birth, during the course of delivery, and subsequent to the infant's actual appearance in the home. All interviews have been conducted by the same investigator and discussed with the two senior investigators. The interviewer has, however, been free to collect material in whatever order best suited the particular family. The outline has not been administered as a questionnaire except as it has once been mailed. Only one interview has been held to gather information about study children. In the case of families already known to CASP the interviewer has had an opportunity to read certain material from the records before carrying out the interview. Nevertheless, in the analysis of the data neither the quality nor the quantity of the information obtained appears to have been conspicuously influenced by such prior knowledge.

The interviewer has addressed himself to the child's reaction and response to the new sibling $(a)$ in the anticipatory waiting period, $(b)$ at the time of birth of the sibling with the coincidental separation from mother, $(c)$ at the time of the mother's return home with the new infant, $(d)$ until the present. In those cases where a home interview has been carried out the study child has been seen and some evaluation of the present status of sibling relationship has been made on the basis of naturalistic observation. 


\section{Analysis of Data}

This pilot study has yielded a rich diversity of material, but the investigators recognize that their data cover too great a scatter of ages in a very small sample, plus too many other variables not controlled for to justify the raising and testing of any hypothesis. Significant variables not controlled for include:

1. House moves (often from another town) just before the birth, or house moves (within Ann Arbor) soon after the birth.

2. Visiting or not visiting mother during her postdelivery hospital course.

3. Father's participation in child care and the extent to which this is increased at the time of sibling birth.

4. The extent of substitute mothering prior to the delivery, that is, the nature of mother's career goals.

5. The extent of separation experienced by the older child prior to the birth.

6. Death of a previous infant.

7. Bilingual families who do not speak English in the home.

The data collected, however, illustrate many different techniques used in introducing first or later siblings to a young child and show equally clearly a broad sampling of the coping mechanisms employed by young children in adjusting to this change in their status. Examples extrapolated from our raw data are presented for discussion.

\section{Variables Selected for Discussion}

It is inevitable that each child's situation will be unique in many ways and will stand independently by itself. To view the many variables that may have influenced the response of a particular toddler or young child it is necessary to study the data collected from the particular parents in their entirety. Here the authors can offer only a general overview of some of the major differences and similarities noted in the analyzed data and more specifically portray a few situations or particular interest.

\section{Preparation of Under-Five-Year-Old Children for the Birth of a Sibling}

In our sample of 21 mothers there is little variation in the time at which an older sibling is told about the mother's pregnancy and prepared for the birth of a new baby. Most mothers informed their 
children in the second trimester near the time of quickening, that is, when they were conspicuously pregnant. Five mothers did not inform their children at all.

\section{No Preparation}

In each of these five cases, the child was age $1 \frac{1 / 2}{2}$ or less at the time of the sibling's birth. The mothers of these children thought of them as too young to notice the pregnancy. In one family where the older male child was only $2^{1 / 2}$ months old when the mother became pregnant again and less than a year old at the time of delivery, the parents said, "We never thought of telling him-and he never asked!"

\section{Early Preparation}

Only two mothers feel they told their children earlier than they later thought to be beneficial. One mother, with a son four years older than his sibling, decided to tell him three months into her pregnancy because she was conspicuously depressed and miserable, and felt obligated to explain this to him. She then became afraid there would be too much time for him to have mild anxieties (he is a very dependent child who has what mother calls "insecurity attacks"). She reports that he accepted the news without response, however, and seemed to forget it in time.

Another mother who feels she introduced the topic too early also experienced a miserable pregnancy. Having had polio once, the pregnancy was a physical strain. Her daughter is $2 \frac{1 / 2}{2}$ years older than her sib, and mother reports, "She would not leave my side, she seemed tense, with pressure inside." When the baby finally came, the older child was "greatly relieved" and accepted her sibling well. It may be that because of the back ailment the child understood the pregnancy as physically hurtful to mother, and needing to be reassured she clung to mother, thus further complicating the mother's experience. This mother feels that telling her daughter at a later point in the pregnancy may not have avoided the child's anxiety but could have delayed the onset, which would have been more comfortable for all concerned. This mother now never tells her daughters of important events until the very last moment. She does not feel convinced that the discomfort the child experienced was in any way alleviated by the reality.

It seems that there is really no way to avoid the introduction of some strain into a young child's life when a new sibling is expected. 
It is doubtful that even a toddler will be unaware of the physical changes in his mother due to her pregnancy especially after "quickening" or to changes being made in preparation for the new sib's living quarters. Hence, informing the very young child of the anticipated birth of a sibling at least adds some reality around which the child can weave his fantasies. The toddler cannot easily comprehend or master the anxiety and fantasies he experiences in association to the anticipated arrival of a new sib, and it seems to us that a certain period of time may be necessary for the young child to elaborate and enact his fantasies in play in order for him to achieve some mastery over the anxiety. The toddler age child, of course, is unable to appreciate the length of time that has to pass before the new sib will be born. In our sample of mothers, it is this factor that seems to be the reason two mothers thought in retrospect that they had introduced the information too early during the pregnancy. In these two cases our data do not warrant the conclusion that if told later these two children would have managed the birth of a sibling more easily.

\section{Preparation}

With children older than $1 \frac{11}{2}$ (usually between 2 and 5 years of age), we find more detailed explanations are given. Reference to other babies in the neighborhood seems to be useful in helping the toddler or young child anticipate his or her new sibling. One negative outcome of this approach, however, appears to be that the child may then want his sibling to look identical to the beautiful, smiling baby next door, and he becomes terribly disappointed on discovering that his new brother or sister is unattractive, cross-eyed, and cries. One mother, a nursery school teacher, took a cute eight-month-old baby to her class one day. The children were delighted. Several weeks later one little girl came to class extremely sad. Suspecting what might be wrong, the teacher questioned her. The four-year-old said, "My new baby brother does not look at all like the baby here." It seems that the mothers in our sample recognized the concreteness of thinking in their young children and used the presence of other new babies in the neighborhood as an aid in preparing the child for what his or her new sibling might look like. Because of this same concreteness, the older child may have difficulty in abstracting and imagining a sibling similar to but not identical with one of the neighborhood babies. It would seem that if reference is made to other babies for explanation, it is best done on a casual basis, referring to several babies and the younger the better. Some older children may be expecting a playmate, and this needs clarifying. In any case ambivalence in the sibling 
relationship will probably lead to disparagement of the imagined or actual sibling.

As noted, the time the parents verbally acknowledge their expectation of another child often coincides with the time of quickening (fourth to fifth month of pregnancy), and many mothers encourage their children to feel the baby move. In most situations there seems to be no contraindication for having the toddler feel a fetal movement. However, one boy, less than 13 months old, was startled and became frightened. The parents laughed at his reaction, and perhaps this added to his confusion. One two-year-old girl reportedly responded by showing bewilderment and confusion, but in most cases the response was merely transient curiosity.

Along with permission to feel the fetal movement goes the explanation of what is inside. One mother gave her 17 -month-old son a doll, saying that there was a baby growing in her "stomach" similar to the doll. Mother says the only disappointment with him during her pregnancy was that he never played with the doll, was not too interested, and seemed confused with the activity in mother's stomach. An inanimate doll is probably not a good enough analogy for the comparison and serves only to confuse reality testing.

As reported by most mothers in this study, children from $1 \frac{1}{2}$ to $3^{1 / 2}$ years old do not seem to be very inquisitive about the pregnancy. Most of the mothers gave simple and concise statements of explanation, for example, "There is a very small baby growing in Mommy's tummy." However, for the late four- to five-year-old, who can verbalize curiosity, a more detailed explanation was given. The five-year-old girl is described as being very angry with her mother for having a baby in her "stomach" which she thought mother was devouring. Not all mothers are able to use exact terms when talking with their five-year-olds, such as using the term "uterus" instead of "stomach." It can be supposed that mothers who use the latter term may support infantile sexual theories of oral conception. The four- to five-yearolds tended to express curiosity about the mechanisms of delivery and often asked direct questions. The five-year-old girl said, "Does it come out of your butt?" Most children, even at five, were less likely to ask how the baby got there. Nevertheless, one mother took the opportunity to explain about sexual intercourse (even using biology textbooks) to her sons, one almost five years, the other three years old. She claims that the almost-five-year-old understood well, but acknowledges that the three-year-old was really confused.

The degree of introduction and explanation was varied in accordance with the age of the child, the mothers in our sample showing a strong tendency to be able to adapt naturally and appropriately 
to the level of their child's cognitive development. While for the younger age child too much information can be confusing, so equally we find at the older age that too little may encourage distortions of reality.

\section{Techniques for Aiding Preparation}

The mothers in our sample were versatile in using various aids to help prepare their young child for the birth of a sibling.

\section{Special Trips and Visits}

Special trips and visits are used as an introductory device by some mothers. The special trip seems to be used as a form of consolation. Going with mother to the obstetrician's office before the birth is felt by some of our mothers to have been helpful in reducing their older child's fear of doctors and hospitals. While normal visits to the doctor's office may be helpful, it seems that extraordinary trips and special gestures may imply to a child that something very bad is expected in the near future and that mother is trying to compensate for this anticipated disaster. Support seems to be received from familiar happenings rather than special events as far as young children are con. cerned.

\section{Use of Children's Books}

Several parents have sought children's books to aid in introducing the topic of an expected sibling, particularly in the case of children older than two years of age. Predominant complaints were that the text was too long for a toddler, the pictures unrealistic, and the emphasis too positive. For instance, one mother described the books as "You go to grandmother's house and everyone is smiling." Only one mother felt that a book she used for her $2^{1 / 2}$-year-old daughter was useful [13]. In general, the comments on children's literature were that none was available or that those available were so poor that they were not used.

\section{Sleeping Arrangements}

An important area of preparation is the expected sleeping arrangements that will be in effect when the new baby arrives, which optimally are planned and announced beforehand. Several parents 
planned for the new baby to sleep in their room. In most situations where the new baby slept with the parents, the older sibling responded with jealousy, sleeping disturbances, and some regression. As was to be expected, the older child's reaction to the sleeping arrangements often epitomized his feelings of exclusion and displacement, and these were the issues dealt with, whether covertly or overtly. One family decided to move the baby out of their room when they discovered that their $3 \frac{112}{2}$-year-old daughter was very jealous and responded "as if the baby had a special privilege which she did not have." The situation may be compounded when the older sibling has been used to sleeping with the parents. One family, from a non-American culture (Korean), explained that sleeping with parents is a tradition of their culture. The older daughter, who now had her own room, refused to sleep there so long as the younger daughter slept in the parents' room.

One mother's way of dealing with a situation that might have ended with a similar problem is interesting. A three-year-old girl slept in the parents' room before the birth of her sister. The new baby was put to sleep in a separate room. The older child was then gradually introduced to another room and a new bed, a hideaway bed, but still had the option to return to the parents' room if desired. Finally when she was no longer sleeping in the parents' room and regularly slept in the new bedroom, the room was declared hers, and she arranged it on her own. It seems she grew into this change easily. The same mother previously had moved her oldest child, a boy who was $2 \frac{1}{2}$ years older than his first sister (the middle child), out of the parental bedroom when this sister was born. Three months after the birth of the middle child the family went on vacation where the oldest boy slept separately from the parents. He was told beforehand that on return home he would have a new room and bed, and he accepted this very well.

Sometimes parents plan for the new sibling to share a room with the older child. One four-year-old boy who was told before the birth that the new baby would sleep in father's den said he wanted the new baby to sleep in his room, not the den. But when the new baby sister was born he never repeated his desire to have her as a roommate. Sharing the same room has its own difficulties. In one family, 12 months after the youngest son was born, a move was made to a new home, where the older brother, $4^{1 / 2}$ years old at the time, had to share a room with his younger brother. From that point on, the older child became a frequent bed wetter and often fought with his brother. Whenever the boys fight, one of them is placed in the guest room. 
Father says, "They always know that room is waiting for them." The separate sleeping place seems to lessen the fighting, but not the bedwetting (this will be referred to later). At the time of the study, the older child likes to sleep with his brother because he is afraid of the dark when alone. In another situation, a boy 13 months older than his sister never did like to have her in the same room-"he couldn't stand it!" When the sister was two months old, the family moved to a new house where he was made to share his room. He became so hostile and aggressive that the parents felt obligated to move the sister out of his room into a hallway. In several of the study families the acceptance of the new sibling into the same room has worked well; where it has not seemed to work the parents have had to find a different arrangement.

Obtaining a new bed. A common aspect of the changes in sleeping arrangement often associated with the birth of a sibling is the introduction of a new bed. In homes where the introduction of a new bed is received well, a common technique seems to have been used. Several months before the birth of the new sibling, the older child has been allowed to oscillate between the old crib and the new bed. He is allowed to return to the "baby crib" if desired, but is encouraged to accept "the big boy's bed." By the time the new baby becomes ready to move from the bassinet to the empty crib, the older child is well established in his new bed. When asked then if his sibling can have the old "baby crib," the older child commonly agrees, implying that the little crib is for babies. One girl, who was $2^{1 / 2}$ years older than her sister, was allowed to pick out her bed 6 months before the birth of the sibling. She quickly accepted the bed, and it seems to the parents that she never made any association to the fact that a new sibling was expected to use her former crib. A boy who was two years older than his sister received a new bed on the day of mother's arrival from the hospital. It was a bunk bed. The new baby did not, however, sleep in his old bed, which was already regular size. He was proud of his bed, boasting of it to peers, and accepted it well as long as his special blanket was present. Finally, in another family, 3 months after the birth of the new sibling, a new bed was introduced to a girl who was $2 \frac{1}{2}$ years older than her sister. For weeks in advance mother had the daughter cutting out pictures of beds she liked and taking them to the nursery to show her peers. When the bed that she had selected arrived, she was very proud and told her friends. The younger sister's use of the old crib was easily accepted in this case.

According to our series of families, the best time to introduce a new bed seems to be before the birth of the sibling so that there is 
less opportunity for the linking of the new bed with inevitable feelings of exclusion and displacement. A further positive maneuver is to allow the older child to participate in the choice of a new bed. However, sometimes a new bed is introduced with success after the birth when parents help the child to anticipate the event, enlist peer support, and retain continuity in use of a transitional object such as a special blanket. It seems helpful if the new bed can be associated with a sense of achievement and not with the necessity for use of the old bed to accommodate the newborn sibling, since the latter contributes to the older child's sense of having been usurped. For the older sib who moves into a youth bed from a crib, this act may represent the giving up of "infantile" ways, and here a sense of achievement may help some children give up what is familiar.

\section{Introduction of a Pet}

Two mothers report that the family pet served as a preparation for the new sibling. A boy, who was $1^{1 / 2}$ years older than his younger sister, learned to play with small, fragile kittens before the birth of his sibling. He was able to witness the birth of the kittens, and this event was immediately related to the forthcoming baby. When his sister was born, he knew how to touch her gently as he had been trained. to be gentle when handling the kittens. In another family, several weeks before the new baby was born (a boy after three girls), there were discussions of anatomical sex differences about the new pet-a male dog. The two oldest daughters were $7 \frac{1}{2}$ and $4 \frac{1}{2}$, while the most immediate daughter was $3 \frac{1 / 2}{2}$ at the time of the birth. The youngest daughter was involved in the older sisters' discussion, so that before the new boy baby came she had already been permitted to ask questions about sexual difference. Though it is impossible to plan a pet with the same sex as the expected baby, a small pet can help a young child to learn gentleness and concern for a helpless infant who cannot yet respond very directly. This may be helpful in preparing for the new sibling who will give limited response for several months, particularly when the older child has a desire for the new sibling to be a personal playmate. The introduction of a pet can also provide some vicarious satisfaction for the young child who may be jealous of mother's childbearing; the pet can serve as a substitute for the envied baby.

Arranging for a Baby-Sitter or "Substitute Mother"

Advance planning to arrange who will baby-sit for the older 
child during the mother's absence for delivery not only seems to help the child's adjustment but also lessens family confusion and thus avoids added stress for mother at the commencement of labor. Several mothers in our study whose deliveries started late at night describe having had great difficulty finding a sitter, which surely complicated the moment. Sometimes the baby-sitter is a complete stranger to the child, but as we would expect, the best situation seems to be to have as the baby-sitter a person quite familiar to the child and someone who is appreciated by child and mother, for instance, the maternal grandmother or an aunt. Some mothers had this person come several days before the expected time of birth. One four-year-old boy witnessed his mother lying on the floor having labor contractions. Two days previous this mother thought she was about to deliver, went to the hospital, but did not give birth. Naturally she wanted to be completely positive before returning there. The son reportedly responded only with curiosity, not fright, probably because the great-grandmother was present, who is described as being "warm, tremendously helpful, and close to him." Of course, it is not always possible to plan exactly in advance. In one situation, mother started to deliver three weeks prematurely at 1:00 A.M. The confusion and hurry of the moment was magnified by difficulty in finding a baby-sitter-not just a special baby-sitter, but anyone at all. Finally, an unfamiliar college girl was located in the same apartment complex. Supposedly the $1 \frac{1 / 2-}{2}$ year-old son did not wake up or witness the departure, but next day was a little startled to find the strange sitter there and mother gone. He acted in a more withdrawn and passive manner than usual-being a "quiet and withdrawn child generally." The potential trauma of the situation seems to have been lessened by the fact that the child had experienced previous nontraumatic separations from mother; now mother was absent for only two days, and father who was close to him made a special effort to spend more time with him. He also was allowed to visit mother in the hospital.

In most situations in our series the child stayed at home during the birth, did not witness the mother in pain or misery, and was with a familiar and friendly baby-sitter. In one case, however, two weeks before the birth, which occurred late in the tenth month of pregnancy, the entire family moved to the grandparents' home. Prior to the birth the 13-month-old son seemed very anxious about the new baby coming and would often ask, "When's the baby coming?" During the mother's absence, which was for five days, he is described as being "nasty" to the grandparents-particularly to grandfather, who says, "He was a real monster!" Father spent time with him then, but there 
was only telephone contact with mother. When mother left the hospital she stayed at the grandparents' for two weeks, since she had had a Caesarean section and felt weak and needed help. This older child became more aggressive after mother's return with the new baby sister. Once he even threw water at the baby, and when she cried he hit her. Mother feels she was "a good baby, did not cry a lot, and certainly did not deserve being hit." When after two weeks the family left the grandparents' house and returned home, he went "wild" with excitement. Such a situation seems to emphasize the importance or value of arranging for the older child to stay at home during mother's absence, instead of moving him to a less familiar setting where he may feel more vulnerable.

The work of Heinicke and Westheimer [14] and that of the Robertsons [11], for example, point to the disruptive force of a brief separation of young children from their parents. James and Joyce Robertson have observed with two children, both approximately $21 / 2$, who they temporarily fostered while the mothers were in the hospital to have babies, that although unhappy and experiencing loyalty conflicts, because of their advanced level of ego maturity and the achievement of reliable perceptual object constancy, these children could retain memories of mother, could be helped to separate fantasy from reality about why the mother was absent, and they could drop the foster relationship appropriately on return home. Two toddlers under two years of age, however, could not be helped to keep the absent mother in mind; because of the urgency of their needs they shifted their loyalty to the substitute mother relatively quickly and experienced difficulties disengaging from this relationship and re-establishing the one with their mothers. The toddler age child may be at the height of his separation anxiety (around 18 months) or at that point in the separation-individuation process where he is consolidating his gains (early rapprochement), so that separation from mother at this point needs to be understood as a potentially disruptive element needing the skillful introduction of positive elements to offset the negative ones. Hence, it is necessary to recognize that the familiar surroundings and routines of the child's home and the familiar face of a loving mother substitute, such as a grandmother, are the kinds of considerations that can help alleviate added strain on the separationindividuation process.

Her departure to the hospital for the birth begins mother's temporary separation from the young child and marks the beginning of intensified stress in his experience of getting a sibling. Some children show separation anxiety and regression. One four-year-old boy, who 
was toilet trained since two, wet the bed the night of mother's departure. We will discuss the type of regression seen, that is, its manifest expression, in a later section of this report. On the other hand, many children in our series seem to have been able to tolerate well the temporary separation from mother. This seems to have happened in situations where solid preparation occurred, the child stayed at home with a familiar person, father was actively involved, and visits to mother were possible.

\section{The Father's Role}

An area not previously stressed in the literature and one that specially interests the investigators is the importance of the father's role in the child's experience of the birth of a sibling. The time when father can be particularly helpful seems to be while the mother is temporarily absent in the hospital. In virtually all of the families in our sample, the father was the person responsible for informing the older child of the actual arrival of the new sibling, the sibling's sex, and the health of mother. The prior and contemporary involvement of father in the older child's life seems to relate directly to the level of adjustment made by the child to the temporary separation from mother and to the degree of acceptance shown to the new sibling. In one situation, where father was favored over mother, no distress was overtly shown over mother's absence. Both the mother's sister and the maternal grandmother helped care for the older child during mother's absence, but mother did not contact him while she was in the hospital. His attachment to father allowed him to deny importance to his new sibling, since the new brother occupied mother's attention, not father's which he claimed for himself. Only when father started to show interest in the new sibling did this older brother express jealousy, and even then this was reportedly of a minor order. Now at the age of two and three years, respectively, these boys are described as being cooperative with most adults and with each other, and able to express aggression on a verbal level. In this family the secure relationship with father seemed to nullify some of the threat of displacement while mother cared for the new sibling. In this particular case, however, we might ask what will happen when the older brother enters the phallic oedipal stage? Will he then become appropriately more attached to the mother? Will he strive to displace his brother, and will the development of rivalry between the siblings perhaps occur? How will the older child's sexual identity be affected? Cases where the father is the primary object or approaching this status pose many questions and merit further study. 
In the sample studied it seems that in those families where a mother is the primary object but father is intimately involved, the stress due to the birth of a sibling may be reduced with children of both sexes. It is only in recent years that we have turned our attention to the role of father as a caretaker individual who can administer to the young child's needs for comfort and support during moments of stress and strain [15]. We are becoming increasingly aware that fatherhood can create an emotional crisis; the more adequately the father is coping and mastering psychological conflict and anxiety related to the pregnancy and delivery, the more he will be able to deal adequately with his older child's anxiety, queries, and needs.

In those situations where father's participation contributed to difficulties he was less able to be empathic to the toddler. In one case where a four-year-old boy experienced the birth of a brother, the father, who had not been interested in him as an infant, was interested in the new sibling, who was born by the Lamaze method. The Lamaze program clearly affected the father's attitude, or, rather, the program appealed to a need of his at the time. The older boy was described as being rather "moody" during mother's absence; it seems likely that this behavior was not unrelated to father's new interest in childbirth. In another situation that developed postnatally, the father was more attached to the daughter than to the older brother. She was a "sweet and pleasant" baby while he had been "difficult and colicky." The daughter was clearly "daddy's child." The son, who is the older by 13 months, showed a great deal of regression as well as hostility toward the baby. In another family where the daughter, 27 months older than her brother, was always closer to father than mother, the birth of a new sibling seemed to push her further from mother and enhance her clingingness to father. This girl has never had difficulty separating from mother but hates to leave father. Even at the age of four, she climbed over father while he read the newspaper, which was quite irritating to him, and she continually begged to be carried by him like a baby. The role of father, which in many ways has been unexamined, can be seen to have special importance in the area of sibling relations, and to be a rich area for further study.

\section{Contacts with Mother during the Period of Hospitalization}

An important factor during the time of the birth is the contact mother makes with the older child, particularly a visit to the hospital. Telephone contact with the older sibling seems most helpful when the child is a late toddler and more verbal. In our sample, telephone 
conversations with mother have been variously described as "hated" by the child, disinteresting to the child, demanding on the child's short attention span, and "exciting just to hear mother's voice." Usually, the telephone conversation with the toddler is very short and simple, centered on such questions as: "When are you coming home?" "How are you and the baby?" One mother, realizing her $3 \frac{1}{2} 2$-year-old daughter's inability to tell time, answered her question concerning mother's expected return home by saying, "Oh, I'll be home Saturday-the day daddy does not work." Whenever a visit to mother in the hospital has not been possible, telephoning or writing letters that father could read seems to have been helpful to the families in our study but surely does not serve as a complete substitute for an actual visit.

In many places hospital policy now permits children to visit mother and see the new sibling. In our study, in every situation where such a visit occurred, it has been described as truly helpful for the older child and usually for the mother as well. Even in situations where mother may have been overprotective in the past, the visiting child, in spite of clinging behavior, often made no great difficulty when leaving mother after the visit. A 1/2-year-old boy was described as "jumping up and down with laughter" during his visit. In this instance, reversal of affect may have been in operation in defense against angry or hurt feelings, while at the same time the activity level itself may have brought relief through discharge of pent-up tension. A 21/2-year-old girl previously described whose mother has had polio was obviously "relieved" to visit mother and to see she was no longer pregnant. Mother took her to the "potty" during the visits, thus keeping a continuity with a familiar home routine. This toddler visited mother each day, and mother's homecoming was described by mother as nothing special-"It was just seeing mother again"-and the clinging behavior decreased after mother's return. One mother was very clever. Her older daughters were only able to see her and the new baby behind a window, so she held up a sign that could be seen through the window and read, "Mother loves you!" The daughters laughed. They've never forgotten the visit, especially the $3 \frac{1}{2}-$ year-old daughter. Seeing the new baby in the hospital was not viewed by our parents as important as visiting mother. One father felt that it was perfectly fine to see the new infant, but it should be seen alone and not in a "mass of other infants and incubators-that may only confuse a young child."

Though in virtually all cases the hospital visit of the older sibling was considered truly valuable, two mothers in our sample had a 
few reservations. One mother, who had a three-year-old son and a two-year-old daughter at the time of the birth, said the visit occurred the day after delivery when she was very tired and haggard looking. The three-year-old son had to be particularly reassured that she had not been hurt by the birth of the new baby. Whether his fear was an expression of his own aggressive wishes or a response to the mother's actual appearance remains an open question. Another child, a boy three years older than his sister and with a history of extensive day care, was allowed to visit his mother five times, once each day of her hospital stay. Once he knew he could visit, he demanded to go, which he did with a different person each time, that is, grandmother, friends of the family, and father. Each time he threw severe temper tantrums when they attempted to separate him from mother to return home. The special circumstance of day care is probably the most significant variable in this case-previous separation from the mother and unsatisfied longing for her, making it especially difficult for him to tolerate the further distancing implicit in the birth of his rival. Perhaps what would have been helpful in this situation is not to have brought the child with various and different persons each time, but always with the same person, someone especially close who could have given

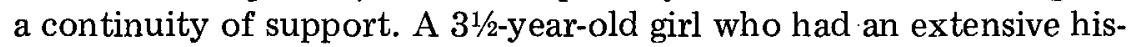
tory of baby-sitters was also brought to visit mother five times-each time, however, by father who was quite close to her and very understanding. He explained each time why mother was in the hospital, that mother was all right, and that mother would be home soon. There were no behavioral problems noted at the end of these visits.

On the basis of the experiences of the families in our sample, it would appear that visiting mother in the hospital seems mostly helpful to the siblings, although occasionally there are difficulties for which both parents and hospital staff should be prepared. It would seem to us that for the very young toddler, where perceptual object constancy is a recent achievement not yet fully consolidated, so that the child has difficulty retaining a clear image of the absent mother, seeing the mother in the hospital or at least hearing her voice over the telephone can go a long way toward reassuring the toddler that "out of sight" does not mean "out of mind."

\section{Gift Giving to the Older Sibling}

Gift giving to the older child seems to vary in its usefulness. The gifts that were best received in our study were toys that the children wanted very much. For instance, one three-year-old boy received a 
toy pistol. His older brothers had guns, and he really wanted one. He cherished the gift. In some ways, giving him the gun may have been like saying, "You're now big like your brothers." Another boy who is very interested in vehicles received a toy truck from his father, one for each day of mother's absence, and these were well received. The typical gift for a girl is a doll, and in most cases these dolls are not well received. For instance, one mother in our sample gave a doll to the older daughter on arrival home, stating, "Here's a gift from the baby." When the daughter (age $3^{1 / 2}$ ) never used it, mother thought the child was responding negatively to the ridiculous idea of "a little baby giving a gift." Mother did not use the gift-giving meth od again. One $2 \frac{1}{2}$-year-old girl was given a doll by her mother during a visit to the hospital. She never played with the doll at home. However, she did play with another doll in the toddler program playroom. Three days after the birth she walked around the room saying, "This is my baby." As already mentioned, a 19-month-old boy was given a doll 2 months before the birth of his sibling as a preparatory device. He never used it either, to the mother's disappointment.

In each situation where dolls were given, invariably they were not accepted as cherished gifts. It may be inferred that the nonacceptance by the children in our sample, of dolls as gifts, was because they preferred the "real thing." Perhaps giving a doll to a three- to five-year-old girl is experienced as somewhat of a narcissistic injury insofar as she may feel she cannot have real babies like mother but only artificial ones. It may be that when it is possible a pet would make a much better gift than a doll. Here the pet would be a living creature to be cared for which could enable the child not only to identify actively with the caretaking mother but also to identify vicariously with the pet receiving the care. Of course, we recognize that a child can often abuse a pet and that aggression may be displaced onto a pet; in some instances indeed such a gift would not be suitable. Since mother and father roles are generally not acted out in play until the beginning stage of the oedipal complex, it would seem to be rather premature to force a baby doll on a small toddler. Thus, gifts that are desired by a child and not imposed on him by adult attitudes, as dolls seem to be, may be more readily received and more helpful. However, as one mother put it, "the best gift a child wants is mother's homecoming." In a way, a gift at this time is meant to be a consolation prize and is somewhat like giving a token present to the sib of a birthday child. Although this may momentarily take "the sting" out of the narcissistic injury, in the long run it does not seem to be very significant. The kind of gift chosen, its appropriateness to 
the child's libidinal phase, and whether the same or opposite sex parent gives the gift can all be significant considerations. As previously mentioned, several fathers gave their sons trucks and one gave a toy pistol; it may be these are a symbolic gesture aiming to enhance the relationship with their sons and underlining the common maleness between them as a reaction to the envy of the procreating woman, but this is speculative. Our data are incomplete, and a more extensive study might go further in attempting to investigate such speculations.

\section{Regression versus Progression}

The discussion of regressive phenomena developing after the birth of a sibling should surely not be omitted here in spite of its extensive exposure in previous studies [2]. A common regression in evidence after sibling birth is increased desire for oral gratification, that is, a renewed desire for a bottle, pacifier, or thumb sucking. As is to be expected we found that oral regression seemed to occur more often in the young toddler age children. It is interesting to note that parents in our study were more disturbed by thumb sucking than by the desire for a bottle. One mother tolerated the use of a bottle in a four-year-old, stating it was "like drinking milk from a straw," but absolutely detested thumb sucking. A concomitant factor often linked with these regressive trends seems to be the sleeping arrangements of the siblings, particularly if the younger siblings sleep with the parents. In one family, with a boy 16 months older than his younger brother, the older child asked for a bottle at night when he observed his brother receive a bottle and be put to bed in the parents' room. A girl who was 14 months older than her younger brother also asked for a bottle at night when seeing that her brother slept with the parents. Four months after his birth, the family moved to a new home where she shared a room with her brother. Her desire for a bottle persisted, then extending to daytime requests also. In fact, the mother stopped her bottle at age $2^{1 / 2}$ exactly when the younger sister stopped at age 1 year 8 months.

As is well established, another very common regression for a toddler age child at the birth of a sibling is in the area of toilet training. In our sample, in each situation when regression occurred in toilet training, there seemed to be other predominating factors in addition to the stress of displacement by a new sibling, that is, overprotectiveness of mother, difficulties in managing aggressive impulses on the part of a parent, and/or the stress of moving to a new home. In one family where the experience of a new sibling for an older child 
occurred twice, toilet training was difficult in one case but not in the other, which this mother felt she could explain. In the first instance, the older brother was $1 \frac{1}{2}$ when his younger brother was born. Seven months after the birth, the family moved from the United States to another country. The older child was frequently cared for by a babysitter who insisted on rapid toilet training and openly voiced her favoritism for the younger sibling. Shortly after the move, the older brother was found smearing his feces over his brother. Mother described his toilet training as "the most difficult in the family." She started training him at two, but he resisted her efforts until age three. By contrast, when the younger boy experienced the birth of his sister when he was three years old, no regression occurred in toilet training. Mother says the younger boy received more attention from her than the older son at a comparable age, and his training had not been forced on him by a maid who openly disliked him. In addition, the younger boy did not experience a change to a new home.

Another child who was four years older than his younger brother also regressed to messing behavior, starting one month after the new baby's birth and continuing for five to six months. He had been well trained supposedly by age two. The first incident occurred at a nursery school, resulting in a special call to mother and her immediate presence at the nursery. Mother says, "It was a great attentiongetter!" This child has a history of frequent tonsillitis and diarrhea between one and two years of age. Toilet training was not achieved until after a tonsillectomy. For this boy the previous illnesses probably contributed to delay in toilet training and a vulnerability in this area, hence the mode of regression with which he responded to the stress of a new sibling. A four-year-old boy, who was toilet trained at two years of age, wet the bed the night mother went into the hospital; here, perhaps, phallic excitement was involved. This boy frequently displayed direct aggression toward his younger sister; for example, he pinched her, squeezed her leg, and put a quarter in her mouth to stop her crying. When she was two months old he had nightmares about her. Mother began putting tight restrictions on his behavior; she even put a sign up that the baby was sleeping so he would be quiet, even though he could not read it. Mother now feels this was too prohibiting and too great a contrast to her former leniency. The boy commenced bed-wetting during the period when these strict prohibitions were being made. This mother feels she made her son too dependent on her before the birth of the younger child, and she now feels he became aggressive because he felt slighted. Thus, regression in bladder and/or bowel control developing after a sibling's 
birth seems to occur when other factors enter in besides the normal stress of the sibling birth. As we would have expected, toilet training seems less likely to break down where mother has been supportive and encouraged the child's autonomy during the time of training. Although in two cases toilet training was delayed until three years and four years, respectively, our data are insufficient to establish that the sibling birth had etiologic significance in these instances.

A disturbance in sleeping was noted in four cases. In three of these the children experienced a move to a new house roughly coinciding with the birth of the sibling, and in addition there was the history of previous separation problems. It is difficult in these cases to assess the amount of significance to place specifically on the sibling's birth. The fourth case, a boy who was 16 months old at the time of his brother's birth, woke frequently asking if his brother was in the parents' room. He also would ask for a pacifier if he knew his brother was nursing. This boy did not experience a move, and here the reasons for the sleeping problem are less equivocal.

Enhancement of development associated with the birth of a sibling is noted by previous investigators [3]. The mothers in our study who report that their child seemed more mature after the birth of a younger sibling are also the mothers who offer a variety of supportive influences, more so than in the families where regressions are conspicuous. The supportive elements referred to are those already discussed, such as early preparation for the birth, successful introduction of any alteration in sleeping arrangements, contact with mother during the period of her hospital stay, and the active involvement of father. Enhanced development occurred in many ways, such as the rapid achievement of toilet training, the ability to play independently, easier separation from mother, and the relinquishment of a special object such as a pacifier. For instance, a boy, who was three years old at the time of his brother's birth, gave up his pacifier two months before the birth. After the birth, when he observed his brother with a pacifier and was asked if he wanted one too, he said, "No, that's not for me, that's for the baby." In another family, a girl, $2 \frac{1 / 2}{2}$ years older than her sister, became completely toilet trained while staying at the grandparents' home 2 months after the birth. It is known that this little girl happens to have been very close to the grandparents.

A young child may rely on identification with the perceived aggressor when facing the experience of sibling birth. It may be that in some cases, whether progression or regression is the outcome is dependent upon which object the child identifies with, namely, the sibling or the parent. Anna Freud [16] has written about the progres- 
sive developmental forces that exist along with regressive tendencies in the immature personality. When progressive developmental forces have gained ascendancy, the likelihood for fixations at earlier levels of development is reduced, insofar as the inner balance of forces that may have reached a pathological homeostasis are once again disrupted when progressive forces manifest themselves. Hence, when this is the case, the child can move to the next developmental stage; when circumstances are better and less strain is imposed, the child can make more adaptive moves, and the possibility of a consolidated developmentally earlier pathological fixation point may be eliminated. This struggle between the progressive and active wish to grow up versus the child's reluctance to give up passive pleasures of infancy can be vividly observed in young children during periods of stress. The birth of a sibling appears to be one naturally occurring event in the child's life permitting the observer to assess the progressive versus the regressive forces in a particular child.

\section{The Expression of Aggression following the Birth of a Sibling}

From a very early time Freud [17: pp. 251-52] recognized that children harbor death wishes toward their new siblings:

It is of quite particular interest, however, to observe the behavior of small children up to the age of two or three or a little older towards their younger brothers and sisters. Here, for instance, was a child who had so far been the only one; and now he was told that the stork had brought a new baby. He looked the new arrival up and down and then declared decisively: "The stork can take him away again!" I am quite seriously of the opinion that a child can form a just estimate of the set-back he has to expect at the hands of the little stranger. A lady of my acquaintance, who is on very good terms to-day with a sister four years her junior, tells me that she greeted the news of her first arrival with this qualification: "But all the same I shan't give her my red cap." Even if a child only comes to realize the situation later on, his hostility will date from that moment. I know of a case in which a little girl of less than three tried to strangle an infant in its cradle because she felt that its continued presence boded her no good. Children at that time of life are capable of jealousy of any degree of intensity and obviousness. Again, if it should happen that the baby sister does in fact disappear after a short while, the elder child will find the whole affection of the household once more concentrated upon himself. If after that the stork should bring yet another baby, it seems only logical that the little favourite should nourish a wish that his new competitor may meet with the same fate as the earlier one, so that he himself may be as happy as he was origi- 
nally and during the interval. Normally, of course, this attitude of a child towards a younger brother or sister is a simple function of the difference between their ages. Where the gap in time is sufficiently long, an elder girl will already begin to feel the stirring of her maternal instincts towards the helpless newborn baby.

Hostile feelings towards brothers and sisters must be far more frequent in childhood than the unseeing eye of the adult observer can perceive.

David Levy [18: p. 456] suggests that any initial aggression by the older sibling, however, seems to be directed mostly toward mother for causing a "change in care, affection, attention, or difference in appearance or routine of the child's familiar world." The Robertsons [11] have also observed aggressive behavior directed at mother after a reunion with her following a brief separation due to childbirth. The results from our sample concur with this observation. The time of direct aggression or hostility toward the baby seems delayed and is not manifest until he becomes more mobile and capable of interfering with toys and possessions of the older sibling. When the younger sibling becomes able to defend himself against attacks by the older sibling, there seems to be a change in the relationship toward mutual respect and cooperation. The children who seem to react mostly as described above are under the age of two years, as Levy noted, and even a little older. An exception is the 13-month-old boy who threw water on his new sister while staying at grandmother's home. Children over three years and particularly from late four to five years old seem to show interest in the baby immediately, desiring to hold it and care for it. Even though the older children between four and five were seemingly interested earlier, a change in the relationship between the siblings still occurs when the younger sibling becomes more active. In fact, some parents say that they did not even think of the phrase "sibling rivalry" until the younger child was about one year old and could move around independently. One girl, 15 months older than her brother, said, when he was from 9 to 12 months old, "He should stay small." Another girl, aged 2/1/2 when her brother was born, became noticeably withdrawn and defenseless at home and among peers. However, when her brother was one year old and becoming more active she showed a positive change from dependence and passivity to independence and assertiveness. Thus, as previously shown, the early response will generally be directed mostly toward mother, the change in the siblings' relationship seeming to occur when the new baby becomes more mobile.

Levy [18] noted an instance where a boy's relation to his boy- 
friends reflected his relation to his sister. Comments made about the older sibling's interaction with peers often seem to parallel the description of his relation to his new sibling, particularly when the interaction represents feelings of a negative nature. A child who is aggressive toward his sibling is also aggressive toward his friends and peers. The girl mentioned above whose mother has had polio was very passive and nonaggressive until her brother was age 1 year and she was age $3 \frac{1}{2}$. This change toward open expressions of feelings previously repressed, especially aggression, was not only observed in the presence of her sibling but also at the nursery among peers. Frequently, interested peers serve as a supportive element in coping with the stress of a new sibling. Before the birth several children said they wanted a new brother or sister, so they could be like their friends. When the baby arrived, they were proud and told their peers of the important news, implying that they were special like their friends for having a younger sibling. Thus, the early treatment of a new sibling may often be a reflection of peer group priorities. Having contact with children who have already experienced the birth of a sibling probably offers a sense of peer support to the older sibling.

An area not previously mentioned by us is the effect of an aggressive and jealous older sibling on the development of a young child. In one family where there was only one year between two boys, the younger brother found it extremely difficult to express himself among peers, supposedly because of the amount of aggression shown toward him by his older brother. A boy, who is 15 months younger than his sister, started to talk around 1 year of age. Since he was also becoming more active then, his sister responded to him with more aggression, whereupon he stopped talking until he was nearly two years old. In a family previously described where the 17-month older boy not only experienced severe sleep disturbances but also showed overt hostility toward his younger brother, it seems this younger brother's speech difficulties and lack of assertiveness may also have been in part an outcome of the older brother's frequent attack. Thus, the influence of a jealous older sibling on the development of a younger sibling is also seen as an area for further study.

\section{Reaction to Breast-Feeding}

Breast-feeding is often a time when the older child becomes very jealous, as frequently reported in psychoanalytic case histories and popularly mentioned by Benjamin Spock [19]. In our sample, in 
every situation where breast-feeding occurred the older child responded with jealousy. One mother, who had breast-fed her older son, stopped nursing his baby brother after 1 month because the older boy, then 18 months old, was excessively angry during the breastfeeding period. He wanted to sit on mother's lap and be read to while the baby was feeding on the opposite side. At first mother granted this request, but soon stopped breast-feeding entirely, stating that the baby had to be fed too often and the older son was very irritated by it. A girl, 21/2 years old when her brother was born, also wanted the mother to read to her during nursing. She also "wanted a turn sucking" as well, but this mother refused* and stopped nursing after three months. The daughter then wanted a bottle like the infant. The parents gave her more attention instead; this seemed to solve the problem. One mother while breast-feeding hid herself from the older daughter, who was $\mathbf{1 5}$ months older. Once when the daughter did see the baby feeding she yelled, "Eat, eat!" as if the baby were eating mother. This mother says she stopped nursing and changed to a bottle after two months-" "It was too inconvenient!" Her older child used a bottle until four years of age, and this was not discouraged but thumb sucking was. Only one mother breast-fed continuously for 10 months in spite of her 11/2-year-old son's comments that she did not spend enough time with him. This mother, however, was experienced with breast-feeding and quite confident.

It seems from our series that when breast-feeding the second child it is not necessarily the solution (as Dr. Spock advises) to nurse out of sight of the older child. Firstly, it is surely inconvenient for mother, and secondly it seems to make the sibling overly curious and confused when the inevitable discovery is made.** It seems that many mothers are able to get around the problem without precipitous termination of the breast-feeding. We wonder if in instances of early termination breast-feeding is conflictive for mothers, as perhaps when unconsciously the nursing situation becomes associatively linked with some defended-against content; hence, feelings accompanying nursing may take on a forbidden meaning.

*The authors would suppose that this mother recognized that acquiescing to an older child's request to nurse might be ill advised because of the probable arousal of very exciting fantasies on the older child's part.

**In the novel The Christening by Frances Steegmuller a young boy witnesses his mother nursing the new baby. In his attempts to describe what he has seen to adult relatives he is repeatedly misunderstood as describing the primal scene. 


\section{Sex of the Newborn Sibling}

The sex of the younger sibling seems to have particular import for the older child who is between four and five years of age. One four-year-old boy observed his mother changing his baby sister's diaper. He was very concerned; he actually verbalized that "she had her penis cut off." He showed regression and overt aggression in subsequent behavior. An 18-month-old boy did not appear to notice the sex of his sister immediately, but as she developed she became more physically adept, which greatly threatened him. It seems likely that the anatomical differences between himself and his sister became significant in the psychological sense only when he entered the phallic stage. Now at age nine, while she is eight, he often says, " $\mathrm{H}$ is my natural enemy." In one family, where the reactions to the birth of a sibling were witnessed twice, there were three children-the oldest a son 13 months older than the middle girl who in turn is 14 months older than the youngest girl. The boy responded with more difficulty to his sister's birth than his sister responded to the youngest's birth. In a family of three older daughters, a male child was a special addition. The youngest daughter, $3 \frac{1 / 2}{2}$ years older than the brother, is known to have been frequently depressed, have temper tantrums, and to have clung to mother after the brother's birth. One four-year-old boy who discovered the sex of his new brother the first day home by observing a diaper change ran down the stairs yelling, "He's like me. He has a penis." The mother thought it was a clear approval by this verbal child. Many children do not have this verbal capacity or else are unable to put feelings into words because of conflict.

While it is difficult for a boy to experience the birth of a sister, when a boy baby is very special in a family his acceptance by an elder daughter may be hard won. A sibling of the same sex can be easier to accept but may also lead eventually to another means of competition as illustrated by the mother who describes finding her five- and sixyear-old boys comparing the size of their penises. It seems here that the important dynamic variables have to do with castration anxieties and penis envy, and because these take on significance predominantly when the phallic phase is reached, specific reaction to the sex of the newborn sibling may be delayed. Rather surprisingly we did not get examples of outright denial of the sex of the sibling in our study.

\section{The Single Child versus the Multiple Child Family}

In families where the child most immediate to the new infant had older siblings this seemed to facilitate his acceptance of the new 
sibling. Often the preparation of the toddler age sibling occurred as part of the mother's explanation and introduction to the older sibling, who was more inquisitive. Sometimes the toddler age child would direct questions to his older sibling rather than to his parents. Often as a consequence of the birth of another child, the older siblings seemed to become closer and to play together more often. In general, it appears that an intermediate child is able to accept sibling birth better than the first child in the family is able to. This may well be due to the support and companionship received from the older sibling as well as the sharing of mother's attention when there is more than one child and the lesser likelihood of maternal overprotection. For instance, of one three-year-old boy the mother says, "You won't believe it, but he has never shown any negative feelings toward his younger brother." While doubtless this is an exaggeration, nevertheless, he had two older brothers aged six and seven, who were very helpful in explaining to him what a baby was like. While mother was absent in the hospital having the baby, and later while mother cared for the baby, the older siblings proved helpful to the youngest child in coping with the novel experience of sibling birth.

\section{The Formation of an Imaginary Companion}

The formation of an imaginary companion during the birth of a sibling seems to be a reaction to mother's "limited withdrawal of attention" [10: p. 185]. Nagera's notion that a neglected, sensitive child may be more prone to developing an imaginary companion under stress is supported in our sample, particularly by one situation where a child who experienced extensive day care developed an imaginary companion during the mother's pregnancy. From age 13 months to 32 months, that is, until three weeks before the birth of his sister, this boy experienced day care for more than 30 hours a week (the mother was working full time). The woman who ran the day care program in her home had three children of her own in addition to the four children she took in. All of the children were younger than he, that is, below the age of three years. The family also shared babysitters with neighbors who were described as being "like parents to him." Although living in separate apartments, the open interactions and activities of the two families were spoken of by mother as being "as close to communal living as one can achieve in such an apartment arrangement." As previously described, this boy visited mother in the hospital five times, once each day during the hospital stay. Each time he was taken by a separate person, the grandmother, neighbors, or his father, and each time he showed severe separation anxiety with 
tantrums when it was time to leave. Then within the first week after the mother's return, he bit the baby and also the grandmother, who was helping out. The most interesting response to the stress of a new sibling was the appearance of his two compansions, Boorgy and Porgy, one month before his sister's birth. The companions could play tennis and baseball like father but were small like himself. Whenever mother or father left him behind, he referred to his companions, begging for his parents to take them along if not him. Thus, being a child continually deprived of the parental attention and support he longed for, he developed more faithful companions at this stressful time. As Nagera [10: p. 194] writes: "In many children, the imaginary companion fills the emptiness, neglect, loneliness, or rejection which the child seems to be experiencing. In this then is nothing conflictual in the neurotic sense. The child is claiming what is after all a genuine right-attention, love, and companionship."

\section{A Move to a New Home}

In our sample, a move to a new home soon after the birth of a sibling seems to be such a strong stress that regression, separation anxiety, and problems with aggression may all be manifested. One mother who left for a 3-day period to prepare the family's new home 3 months after the birth found, on return, that her 22-month-old son "would not let [her] out of his sight." Six weeks after the move, he developed sleep disturbances, demanding mother's close presence at night for four to five months. It should be mentioned that this mother attempted to make her son's new room identical to the old one, perhaps adding to his confusion about the change of house. A boy $1 \frac{1}{2}$ years older than his younger brother experienced a move to another continent 6 weeks after the sibling's birth and became more withdrawn. One month later he was found smearing feces over his sibling. A girl, 14 months older than her new sibling, accepted her new sister very well, continuing to be a very open and active toddler. Four months later the family moved and the girls started sharing a room. She became very withdrawn and unable to defend herself, regressed in her ability to dress herself, developed sleep disturbances, and did not achieve toilet training by the usual time. A boy 3 years 2 months older than his brother experienced a move from out of state 12 weeks after the birth of the brother. Soon after the move, severe bed-wetting developed, and he also regressed to wanting a pacifier; this mother had him buy it with his "own money." There are several cases in the study series where moves had similar effects on the older sibling. It seems, therefore, that a move, which removes the security of a child's 
known environment, provides a type of stress that may trigger maladaptive reactions when coinciding with the stress of a sibling's birth.

Since the birth of a new child often means that a family requires more space, a move to a new apartment or home is an event frequently coinciding with the birth of a new child. On the basis of our study it would seem that al though a move soon after the birth of a sibling need not be a very stressful event it often is, and this seems to be an area that merits further study. For young children and toddlers, the familiar is reassuring while the unfamiliar is most often perceived and experienced as threatening; depending on the particular child such additional stress at the time of the birth of a new sibling can only put additional strain on the coping process.

\section{Parental Attitudes}

This study has, if nothing else, highlighted the dilemma of observers faced with a plethora of variables, all with weighty significance for their topic. While focusing on the child's reaction to the birth of a sibling we are very aware that behind the child's reaction and impinging on it are the parental attitudes. It is not possible to give this the attention and scrutiny that its significance merits. Generally it has been noted that the parents' comfort or discomfort in anticipating the introduction of the sibling sets the stage for the child's reaction. Two examples suffice to illustrate this. The first concerns the mother of a boy four years old at the time of her delivery of the planned second infant. This mother expressed some guilt over imposing a sibling on him, and we can wonder if she may not have been especially sensitive to her small son's oedipal overtures at the time. However, both parents subtly confirmed the youngster's ambivalent anticipation of his sibling. Attempts to expiate the parental guilt by arranging a special vacation with him before the birth seem to have convinced the boy that he did indeed have something to fear from the expected intruder. His fear must have received further reinforcement from the immediate predelivery day, which was called his special day on which mother said she would do something special with him, "anything he wanted," at the same time letting him know that she expected to get the baby later that day. Not surprisingly, the adjustment to the sibling's birth was made with difficulty, and there was marked evidence of stress.

In contrast to this, our second example is of a mother who, though fearful that her two-year-old boy would react badly to the news, was not herself conflicted about enlarging the family. This mother was able to help the child make a good adjustment. He was 
five years younger than the next older sibling and much babied by the two older boys. Although the mother had expected a negative reaction he was able to respond well to her early information giving. She took him along when making an office visit to her obstetrician and on the way home told him there was going to be a new baby. Later this mother used children's stories to extend the topic, made references to neighborhood babies, and encouraged the two older boys to help explain what it would be like having a baby in the family.

\section{Complementary Mothering}

Of particular interest to us are the eight children who prior to the birth of the sibling experienced varying amounts of day time care by women other than the biological mother. Although a tendency toward a particular response, that is, withdrawal, has been noted among these children, we hesitate to place emphasis on it because of other variables present among this small series. The impinging variables considered to be most influential in this series of eight are the considerable differences regarding daily or weekly duration of alternate child care, the fact that several of the families are not speaking English in the home, and in addition several have had recent home moves.

The eight mothers did not all work full time. Three did, but the others worked various part-time schedules. Thus there was a range in the quantity of required baby-sitting, and the influence of complementary child care was viewed in various intensities. The manner of child care was also not consistent through the series and ranged from the child being cared for by grandmother to being left with a group of small children in a woman's home. Likewise, in some cases there were several changes of sitters and in others continuity of the same sitter.

The effect of partial daytime separation from mothers who worked only part time before the sibling's birth was not appreciable. If anything, the older child seemed more able to accept the temporary separation at the time of birth, thus reducing the stress of mother's absence. On the other hand, in situations where the older child had experienced extensive daytime child care away from mother we found a tendency to react to sibling birth by withdrawal. Consistently in such cases the personality of the older sibling was described as withdrawn, passive, and nonassertive. One family, with a boy 18 months old at the time of his sibling's birth, moved to another country when the new baby was 4 months old; both children were then cared for by a full-time maid. This boy had always tended to be withdrawn, but then the withdrawal increased markedly. With the birth 
of a third child this mother arranged to care for the older siblings herself, and the second child did not withdraw at the birth of the third.

A boy $2 \frac{1}{2}$ years old at the time of his sister's birth had been cared for by baby-sitters from the age of 3 months until 2 years for more than 40 hours per week. The sitters were women who were personal friends of the family with similar age children of their own. This mother described her son as always "too quiet, too obedient, and too nonassertive." When his sister was born he became very withdrawn, so that mother decided to quit her position at the university in order to spend the time with her children. Mother told the interviewer that the second child, who received more direct mothering, was "more mature and advanced in all ways than her brother" at a comparable age. When the second child experienced a sibling's birth while still a toddler she was able to handle it much better than her brother had handled her birth. This mother expresses satisfaction over her decision to quit professional life until her children are older. She feels "they have clearly benefitted from it" and that the eldest, who has had so many difficulties, is now slowly learning to express himself, since she has been more available to him as a mother.

Thus our sample seems to indicate that although part-time child care by a sitter need not adversely affect the reaction to sibling birth, this cannot be said of extensive daytime separation from mother. Extensive maternal substitution, even by one regular and known person, seems to promote in some instances a tendency to passivity, and under the stress of sibling birth such children are prone to withdrawal and do not have more appropriate means available to cope with the experience. We may surmise that the young child who has not had ample opportunity to experience and express both love and anger in his relationship with his mother is indeed at a serious disadvantage. When faced with an intruder and rival in a relationship that has never been allowed to unfold fully enough, such a child with many previously unmet longings is on the one hand too discouraged to be active in protest and on the other, dare not mobilize aggression lest it destroy what little he does have. When fusion of drives has not been achieved within the ambiance of a satisfying primary object relationship the child may not have easy access to appropriate means of drive discharge.

\section{Conclusions}

The sample examined is too diverse in nature and presents too many uncontrolled variables to allow valid generalizations to be made 
or trends to be reliably described. Nevertheless, the data do provide illustrative material of the manner in which the study families, homogeneous with respect to being college educated, have prepared preschoolers for the birth of a sibling and how these children responded to such preparation.

It is found that the parents have not attempted to prepare children under 18 months of age and that explanation has seldom been attempted earlier than 2 years. Some parents then make use of children's books on the topic and use neighborhood babies as illustrative material.

A number of the study mothers delivered in a hospital that permits visiting of the mother by the preschool child. Most of these mothers found this to be a positive experience which they judged to be helpful to their older child.

In some families the father becomes more involved in child care during the mother's hospitalization for delivery. In most cases he is the person who tells the older child about the birth. Where the father is able to be especially active in caring for the older child the stress of sibling birth seems to be conspicuously diminished, and the child appears to use the increased attention from the father to offset other changes in his life situation.

According to the age of the child the most common regressions appear to be demands for restitution of the bottle or pacifier and interference with toilet-training achievements. The slightly older child often shows a forward move in some area of ego functioning, mastering the situation progressively. Older siblings exposed to breastfeeding all found this a difficult experience, expressing various degrees of jealousy and resentment. The negative feelings of the older child are almost always expressed directly toward the mother over all aspects of the sibling's appearance. Very often it is not until the infant is old enough to intrude upon the possessions and into the play of the older child that he becomes the recipient of direct aggression.

Among situations seeming to increase the difficulty of adaptation to the new sibling we find such happenings as a contemporaneous move to new living quarters, placing the baby's crib in the preschooler's room, or the circumstance of continuous full day care by women other than the mother for a considerable time prior to the sibling's birth.

The study indicates many variables for further study. Of these, two have special relevance at the present time, namely, the developmental consequences of the father's involvement in child care and the developmental consequences of extensive daytime care by an adult other than a parent of the child. 


\section{References}

1. Winnicott DW: The Child, the Family, and the Outside World. London, Penguin Books, 1964.

2. Moore T: Stress in normal childhood. Hum Relations 22:3, 1969.

3. Einstein G, Moss MS: Some thoughts on sibling relationships. Soc Case Work 48:9, 1967.

4. Henchie V: Children's reactions to the birth of a new baby. Unpublished Child Development Report, University of London Institute of Education, 1963.

5. Powers E: Children's adjustment to a sibling's birth and its relation to ego functions. Unpublished dissertation, Boston University, Dissertation $\mathrm{Ab}$ stracts International, 30 (5-B) 2426 B, 1969.

6. Moore TW, Ucko G: Four to six: Constructiveness and conflict in meeting doll play problems. J Child Psychol Psychiat 2, 1961.

7. Levy DM: Study in sibling rivalry. Research monograph 2, American Orthopsychiatric Association, 1938.

8. Ucko LE: Early stress experience mirrored in the world play of five year old children. Hum Dev 10, 1967.

9. Robertson MM: An investigation into the effect of the birth of a sibling using the London Doll Play Technique. Unpublished Thesis in Child Development, University of London Institute of Education, 1964.

10. Nagera $H$ : The imaginary companion: Its significance for ego development and conflict solution. Psychoanal Study of the Child 24, 1969.

11. Robertson J, Robertson J: Young children in brief separation: A fresh look. Psychoanal Study of the Child 26, 1971.

12. Thomas A, Birch $\mathrm{HG}$, Chess $\mathrm{S}$, et al: Individuality in responses of children to similar environmental situations. Amer J Psychiat 117, 1961.

13. Audry AC, Kratha S: Hi, New Baby. New York, Simon \& Schuster, 1970.

14. Heinicke CM, Westheimer IJ: Brief Separations. New York, International Universities Press, 1965.

15. Newsome J, Newsome E: Infant Care in an Urban Community. London, Allen \& Unwin, 1963.

16. Freud A: Normality and Pathology in Childhood. New York, International Universities Press, 1965.

17. Freud S: Interpretation of Dreams. Standard Edition, vol 4. London, Hogarth Press, 1958.

18. Levy DM: Hostility patterns in sibling rivalry experiments. Amer J Orthopsychiat 13, 1943.

19. Spock BM: Baby and Child Care. New York, Pocket Books, 1969. 